\title{
"Preso por ter cão, preso por não ter cão!":
notas a partir de O alienista,
de Machado de Assis preso por não ter cão!":
notas a partir de O alienista,
de Machado de Assis preso por não ter cão!":
notas a partir de O alienista,
de Machado de Assis
}

Noemi Moritz Kon*

132

A apresentação e a análise da famosa novela "O alienista" do escritor brasileiro Joaquim Maria Machado de Assis, publicada em 1882 em Papéis avulsos, serve aqui de suporte para uma breve discussão dos aspectos ideológicos e mercadológicos que orientam os atuais procedimentos diagnósticos e terapêuticos relativos às psicopatologias. Tais aspectos, corporificados nos manuais psiquiátricos, conformam e estabelecem um determinado discurso e fazer médicos, ao mesmo tempo que fabricam as drogas e as doenças mentais que supostamente combatem.

Palavras-chave: Joaquim Maria Machado de Assis, literatura, doença mental, ideologia

* Instituto Sedes Sapientiae (São Paulo, SP, Br). 


\section{MOVIMENTOS LITERÁRIOS}

Optando pelos confins do mundo civilizado, instalando-se no lado ignorado do Oceano Atlântico, o dr. Simão Bacamarte, "filho da nobreza da terra e o maior dos médicos do Brasil, de Portugal e das Espanhas", certificado pelo próprio el-Rei, busca assegurar seu lugar na história, cobrir-se de "louros imarcescíveis", ao ampliar ainda mais os domínios imperiais da razão, ao descobrir e governar "o recanto psíquico", um novo continente. Não, não mais as Américas de Colombo e Cabral, com sua riqueza e barbárie, que já haviam sido, a essa altura, repartidas e espoliadas pelos abutres da Europa Central, mas, sim, um continente inédito, ainda incógnito, ainda mais obscuro e distante, o continente da loucura.

"Trata-se, pois," - diz o explorador Simão Bacamarte - "de uma experiência que vai mudar a face da Terra. A loucura, objeto dos meus estudos, era até agora uma ilha perdida no oceano da razão; começo a suspeitar que é um continente".

Equipado com as armas do pensamento positivo e jovial do cientificismo ingênuo, próprio ao século XIX, dignificado como representante da jurisdição colonialista, afiançado pelos poderes reais - humanos e celestes -, o dr. Simão Bacamarte utiliza como meio de conquista da "saúde da alma" o olho clínico do médico cientista.

"Uma volúpia científica alumiou os olhos de Simão Bacamarte".

Ele "traz de olho", vigia, escaneia - classifica e organiza - a pobre vila de Itaguaí, na caça de espécimes para sua estufa, a "Casa Verde", seu sanatório de pesquisas.

É o olho do médico que, ao despojar-se da experiência mundana, aposta no experimento - este recorte controlado da experiência "conveniente aos olhos", que busca a confirmação da teoria considerada $a$ priori como universal, atemporal e verdadeira -, que retalha a realidade de modo a fazê-la caber em seus próprios moldes. 
Seus olhos "empanados pela cogitação", "acesos da convicção científica", "olhos agudos como punhais", "olhos de metal, duro, liso, eterno", "cegos para a realidade exterior, videntes para os profundos trabalhos mentais", são olhos "que se alongam pelo horizonte adiante, que devassam o futuro com todas as suas auroras", são "olhos que metem medo aos mais heroicos", são, enfim, "olhos do dono da casa".

São os olhos da Razão, são os olhos da Ciência: "da razão puramente científica", desta "coisa séria, [que] merece ser tratada com seriedade", "pois que tem o dom de curar todas as mágoas", e que se traduz em atos de alienista, atos que não precisam ser justificados perante "leigos e rebeldes", que não precisam ser justificados perante "ninguém, salvo aos mestres e a Deus".

São os olhos da transcendência; olhos que não se veem naquilo que veem, que não se dão como "coisa visível aos olhos da multidão".

Frio e distante do pulular da vida, do pulular dos encontros mundanos, das paixões e desejos, o olhar-bisturi do cientista deve poder desvelar a realidade que está muito além da decodificação cotidiana das "versões populares".

Simão Bacamarte é sujeito de seu objeto de estudo, é sujeito de sua vida, e faz do conhecimento, sua crença científica, o guia para suas paixões regradas e desafetadas.

Não pode se perder no desamparo da experiência, do acontecimento e da opinião, nos contatos e contratos do senso comum. Sua esposa é aquela talhada para lhe fornecer descendentes - descendentes que jamais vieram -, seus pacientes, seus diagnósticos e seus métodos terapêuticos são talhados para estarem contidos em suas teorias que, aliás, pendulam entre pontos extremos e antagônicos, mantendo apenas a lógica interna da separação rígida - um verdadeiro abismo - entre a loucura e a razão.

Vale a pena seguir bem de perto e com atenção o desenrolar progressivo de sua doutrina e dos acontecimentos que dela derivaram.

Em sua primeira versão, a teoria das moléstias cerebrais foi assim formulada:

"Suponho o espírito humano uma vasta concha, o meu fim (...) é ver se posso extrair a pérola, que é a razão; por outros termos, demarquemos definitivamente os limites da razão e da loucura. A razão é o perfeito equilíbrio de todas as faculdades; fora daí insânia, insânia e só insânia."

Do pensamento à ação e o obstinado cruzado parte para sua caçada higienista às novas bruxas e o resultado não tarda: quatro quintos da população são aposentados em sua "Casa Verde".

"Insânia, insânia e só insânia: tudo era loucura".

Alheio às revoltas dos itaguaienses, que querem ver por terra o tirano e a "Casa Verde" - "essa Bastilha da razão humana" -, estrangeiro às leis e à administração vicariante dos homens, afiançado pelo poder que mais vale, é apenas e tão 


\section{MOVIMENTOS LITERÁRIOS}

somente no exame dos fatos estatísticos que o alienista encontra a orientação para o indispensável aperfeiçoamento de suas hipóteses.

E é assim que uma nova convicção se faz necessária: "a verdadeira doutrina não era aquela", ["a teoria que excluía da razão todos os casos em que o equilíbrio das faculdades não fosse perfeito e absoluto"], reformula humildemente o sábio, "mas a oposta, e portanto, que se devia admitir como normal e exemplar o desequilíbrio das faculdades e como hipóteses patológicas todos os casos em que aquele equilíbrio fosse ininterrupto".

“- Preso por ter cão, preso por não ter cão!", redarguiram, em vão, os infelizes de Itaguaí.

O certo é que as crônicas da pequena vila indicam que nestas novas condições, ao menos, foram escassos os hóspedes da "Casa Verde" e que lá ficaram por brevíssimo tempo dada a presteza e a excelência da terapêutica do alienista.

"Com efeito, era difícil imaginar mais racional sistema terapêutico. Estando os loucos divididos por classes, segundo a perfeição moral que em cada um deles excedia às outras, Simão Bacamarte cuidou em atacar de frente a qualidade predominante. Suponhamos um modesto. Ele aplicava a medicação que pudesse incutirlhe o sentimento oposto; e não ia logo às doses máximas - graduava-as, conforme o estado, a idade, o temperamento, a posição social do enfermo. Às vezes bastava uma casaca, uma fita, uma cabeleira, uma bengala, para restituir a razão ao alienado; em outros casos a moléstia era mais rebelde; recorria então aos anéis de brilhantes, às distinções honoríficas etc.”.

No fim de cinco meses e meio estava vazia a "Casa Verde".

"Todos curados!"

Todos curados?

E aqui desponta, ainda mais fulgurante, a mestria de Machado de Assis.

Simão Bacamarte, "metido em si mesmo, estranho a todas as coisas que não fossem o tenebroso problema da patologia cerebral, de súbito, parou e perguntou a si":

"- Mas deveras estariam eles doidos, e foram curados por mim, ou o que pareceu cura não foi mais do que a descoberta do perfeito desequilíbrio do cérebro?"

Em Itaguaí não viveria, então, um só mentecapto? Ou, pelo contrário, Itaguaí não possuiria um único cérebro concertado? Tais dúvidas sacudiram o alienista que, atormentado, chegou mesmo a imaginar que estas seriam capazes de "destruir o largo e majestoso edifício da nova doutrina psicológica".

Medonhas tempestades morais desabaram sobre o ilustre médico. Mas os fortes, como Bacamarte, robustecem-se diante da dúvida, não sucumbem a ela:

"Isso é isto. Simão Bacamarte achou em si os característicos do perfeito equilíbrio mental e moral; pareceu-lhe que possuía a sagacidade, a paciência, a perseverança, a tolerância, a veracidade, o vigor moral, a lealdade, todas as qualidades 
enfim que podem formar um acabado mentecapto. Duvidou logo, é certo, e chegou mesmo a concluir que era ilusão; mas, sendo homem prudente, resolveu convocar um conselho de amigos, a quem interrogou com franqueza. A opinião foi afirmativa.":

"Nenhum defeito", "Nenhum vício", "Tudo perfeito!".

Não havia mais o que questionar. O alienista, "ato contínuo, recolheu-se à Casa Verde". "-A questão é científica, dizia ele; trata-se de uma doutrina nova, cujo primeiro exemplo sou eu. Reúno em mim mesmo a teoria e a prática".

O ilustre médico, "com os olhos acesos da convicção científica, trancou os ouvidos (...) e, fechada a porta da Casa Verde, entregou-se ao estudo e à cura de si mesmo".

"Dizem os cronistas que ele morreu dali a dezessete meses no mesmo estado em que entrou, sem ter podido alcançar nada. Alguns chegam ao ponto de conjeturar que nunca houve outro louco além dele em Itaguaí mas esta opinião fundada em um boato que correu desde que o alienista expirou, não tem outra prova senão o boato; e boato duvidoso (...). Seja como for", e este é o encerramento do conto, "efetuou-se o enterro com muita pompa e rara solenidade".

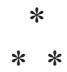

Ora, a potência ficcional de Machado de Assis avoluma-se ainda mais em sua força de construção de realidade quando lembramos que à época da publicação de $O$ alienista, o ano de 1882, um outro Simão Bacamarte brilhava na já iluminada Paris: ninguém mais, ninguém menos do que o iminente neurologista Jean-Martin Charcot.

Jean-Martin Charcot (1825-1893), menos modesto, parcimonioso e circunspecto que o nosso alienista, celebriza-se, desde o ano de 1862, no salão nobre do Hospital Geral da Salpêtrière, o maior hospício da república da França, que encerra atrás de seus muros mais de cinco mil supostos enfermos. No centro do tablado, exibe ao público atento - médicos, intelectuais, estudiosos, cientistas, homens da boa sociedade - sua estrela predileta, Augustine. Ela desempenha o papel com perfeição: o sorriso discreto, o corpo lânguido, quase entregue, impõem a mesma sedução que recende a diva Sarah Bernhardt. $\mathrm{O}$ auditório suspira sem despregar os olhos. O mestre se adianta e, passos cadenciados, coloca-se na boca do palco, dificultando a visão. Com o dedo em riste, olhos penetrantes, dirige o espetáculo e, num passe de mágica de puro hipnotismo, faz de sua assistente uma verdadeira histérica.

Sua missão não parece diferir em princípio daquela do dr. Bacamarte: "estudar profundamente a loucura, os seus diversos graus, classificar-lhe os casos, descobrir enfim a causa do fenômeno e o remédio universal". Mas sua perspectiva é outra: Charcot não quer demarcar em definitivo os limites da razão e da loucura. Ele, 


\section{MOVIMENTOS LITERÁRIOS}

diferentemente do alienista brasileiro, tem prazer em jogar com sua sedução. E, a partir desse encontro, a loucura vai criando, bem aos poucos, também aqui, na periferia do mundo, o seu lugar no centro da cena.

Entre os espectadores do dr. Charcot, destaca-se na plateia um jovem médico vienense, neurologista como o anfitrião, e que se tornará, alguns anos mais tarde, um afamado artífice das paixões: o dr. Sigmund Freud. Nessa cena instituinte da futura criação da psicanálise, colocada em imagem na tela do pintor Pierre André Brouillet, Uma aula do Dr. Charcot na Salpêtrière, de 1886, é formulada não a exclusão da desrazão - como ambicionaria o dr. Bacamarte em seu sonho alucinado de cientista -, mas, sim, o fascínio que dela emana; não a separação abismal e definitiva entre razão e loucura, mas, sim, o desejo por sua experiência trágica.

De lá para cá, alguns tantos, mas nem todos, se atreveram a brincar no interior dessa nova cena, a cena do inconsciente freudiano, abrindo espaço para o encontro criador de sentidos - que é o fundamental da experiência psicanalítica -, abrindo espaço para o desamparo e a sexualidade, para a fúria e o desejo, para o conflito e o sintoma expressivo, para a linguagem, para a alteridade, para o que pulsa em nós, ou seja, para o inacabamento do humano em seu destino trágico.

Contudo, poderíamos ainda nos perguntar: qual a pertinência de "O alienista" para os dias de hoje? Não teríamos, então, alcançado um estado de coisas que nos distanciaria das mazelas e querelas narradas nas antigas crônicas da pequena Itaguaí?

Não, não creio.

A argúcia ácida da literatura de Machado de Assis é imanente a qualquer tempo.

Basta abrir as páginas dos jornais e revistas de divulgação para constatar que o terror à loucura - àquilo que difere, ao que chama aos olhos - e a ânsia por sua aniquilação são bons de ibope e de negócios: obesos e esquálidos, altos e magros, lisos e crespos, duros e moles, ansiosos e apáticos, deprimidos e eufóricos... há terapias para qualquer excesso ou carência, há plásticas para qualquer sobra ou falta e há, também, "pacientes" ávidos para consumi-las. E assim, constata-se que os efeitos da "matraca"1 publicitária dos velhos tempos permanecem bem atuais, e que

${ }^{1}$ Vale a pena conhecer de perto o "caso de matraca": "Esta expressão não tem equivalente no estilo moderno. Naquele tempo, Itaguaí que como as demais vilas, arraiais e povoações da colônia, não dispunha de imprensa, tinha dois modos de divulgar uma notícia; ou por meio de cartazes manuscritos e pregados na porta da Câmara, e da matriz; - ou por meio de matraca. Eis em que consistia este segundo uso. Contratava-se um homem, por um ou mais dias, para andar as ruas do povoado, com uma matraca na mão. De quando em quando tocava a matraca, reunia-se gente, e ele anunciava o que lhe incumbiam - um remédio para sezões, umas terras lavradias, um soneto, um donativo eclesiástico, a melhor tesoura da vila, o mais belo discurso do ano etc. O 
a obsessão pela classificação, ordenação e pela busca de elixires para as alardeadas doenças mantém-se fashion, isto é, bem na moda.

Talvez difiramos na questão dos "estipêndios", como outrora se dizia, ou seja, na questão dos honorários. Simão Bacamarte abriu mão dos seus, pois que se tratava de fazer experiências de alto valor psicológico e, portanto, nenhum interesse alheio à ciência o instigava.

Faríamos o mesmo?

Desnecessário reafirmar a exigência implícita ao capitalismo "desenvolvido", ou seja, da construção ativa de um mercado consumidor "instruído" e receptivo para assimilar a produção e, portanto, apta ao giro lubrificado dos negócios. Se o Brasil, este além-mar periférico, já foi comprador de patins de gelo ingleses logo na abertura dos portos às nações mui amigas, em 1808, por que não seria também o parceiro ideal para a desova de pneus velhos e de novíssimos medicamentos?

Quanto mais giro, mais dinheiro em caixa.

A indústria e o discurso publicitário instruem certos agentes da "saúde" que se fecham, convenientemente, ao olhar crítico e que se passam por revendedores de seus produtos. Dessa forma, decresce a angústia por não saber o in-sabível e cria-se uma demanda por aquilo que já está disponível e pronto para o consumo: novas síndromes, novos transtornos, novos espectros, com suas drogas, máquinas e terapêuticas correspondentes, dispostos sedutoramente nas repletas gôndolas, iguaizinhas àquelas de cereal matinal. E há sempre a necessidade de ampliação de mercado: implementação do consumo de fármacos para os que entram nele, os mais jovens (crianças travessas, ou, na linguagem cientificista, hiperativas com déficit de atenção), ou para aqueles que ainda não sofrem, mas que, certamente, teriam interesse de se resguardar de sofrimentos futuros.

Para o alienista alienado moderno, alheado não mais apenas na ciência, mas, também, no mercado - e bem sei que não são todos -, este douto em títulos globalizados, que recebe acréscimos em sua conta bancária por meio das porcentagens doadas pelas drogarias e laboratórios, que tem suas viagens de férias financiadas nos congressos científicos internacionais, organizados pelas grandes multinacionais

sistema tinha inconvenientes para a paz pública; mas era conservado pela grande energia de divulgação que possuía. Por exemplo, um dos vereadores, - aquele justamente que mais se opusera à criação da Casa Verde, - desfrutava a reputação de perfeito educador de cobras e macacos, e aliás nunca domesticara um só desses bichos; mas, tinha o cuidado de fazer trabalhar a matraca todos os meses. E dizem as crônicas que algumas pessoas afirmavam ter visto cascavéis dançando no peito do vereador; afirmação perfeitamente falsa, mas só devida à absoluta confiança no sistema. Verdade, verdade, nem todas as instituições do antigo regímen mereciam o desprezo do nosso século." 


\section{MOVIMENTOS LITERÁRIOS}

da indústria farmacêutica, e que ratificam tautologicamente o valor das curas por sua presença nos grandes eventos e na mídia, tal realidade das coisas parece constituir um campo de certeza.

Pois as moléstias e as posologias nascem no mesmo berço: e, como é sabido, tudo é uma questão de origem. ${ }^{2}$

Para finalizar, gostaria de destacar o levantamento elaborado pelo jornalista Luiz Caversan, da Folha Online, ${ }^{3}$ que reuniu as listas de classificação das doenças mentais no mundo ocidental cujos critérios foram estabelecidos basicamente por duas entidades, a Organização Mundial de Saúde (OMS) e a Associação Americana de Psiquiatria (APA, na sigla em inglês): são os manuais diagnósticos conhecidos como DSM - nome derivado da sigla em inglês de Diagnostic and Statistical Manual of Mental Disorders, isto é, Manual de Diagnóstico e Estatística dos Distúrbios Mentais - e CID, Classificação Internacional de Doenças da OMS das Nações Unidas. ${ }^{4,5}$ Não é o caso - embora pudesse ser bem interessante - de apresentar aqui a lista completa dos distúrbios mentais arrolados, pois são mais de duas centenas e meia de inserções. Mas, certamente, como demonstra a pesquisa do jornalista, você encontrará nela a classificação exata para sua inadequação ao mundo que nos cerca.

E dá-lhe Machado: sob os olhos do grande mercado, estamos todos nessa. "Presos por ter cão, presos por não ter cão!"

${ }^{2}$ Para aqueles que se interessam pelo tema da "criação de doenças", pela ideia do processo de "medicalização da vida", que hoje é conhecido como "disease-mongering" (algo como "apregoar doenças", ou 'fabricação de doenças') sugiro o site http://observatorio.ultimosegundo. ig.com.br/artigos.asp?cod=378ASP002, que traz na íntegra o interessante artigo de Marcelo Leite, "Hipocondria de resultados", publicado na Folha de S. Paulo, no domingo, 23 de abril de 2006.

${ }^{3}$ Para ler a íntegra do artigo procure Folha Online - Pensata - Luiz Caversan - 'Escolha a sua loucura...”, www1.folha.uol.com.br/folha/pensata/ult513u222.shtml

${ }^{4}$ Para conhecer as classificações do DSM-IV é possível consultar o site Psiqweb, www. psiqweb.med.br/.

5 Dois outros artigos bem interessantes, publicados recentemente na imprensa local, "Acordei doente mental" de Eliane Brum, publicado na Revista Época (http://revistaepoca.globo. com/Sociedade/eliane-brum/noticia/2013/05/acordei-doente-mental.html) e "A moral psiquiátrica” de Vladimir Safatle, publicado na Folha de S. Paulo (http:/www1.folha.uol.com.br/ colunas/vladimirsafatle/2013/10/1349847-a-moral-psiquiatrica.shtml) trazem também reflexões críticas sobre os efeitos da mais nova atualização dos manuais diagnósticos, o DSM-V, lançado em maio de 2013 (em versão impressa, mas também em e-book e aplicativos para dispositivos móveis, tablets e smartphones). 


\section{Referências}

Brum, E. (2013). Acordei doente mental. Revista Época, São Paulo. Recuperado de <http:// revistaepoca.globo.com/Sociedade/eliane-brum/noticia/2013/05/acordei-doente-mental.html>.

Carvesan, L. (2006). Escolha sua loucura. Folha Online - Pensata. Recuperado de <http:// www1.folha.uol.com.br/folha/pensata/ult513u222.shtml>.

Leite, M. (2006). Hipocondria de resultados. Folha de S. Paulo, Caderno Mais, 23 de abril de 2006. Recuperado de <http://www1.folha.uol.com.br/fsp/mais/fs2304200608. htm $>$.

Machado de Assis, J. M. (1882). O alienista. In Papéis avulsos. Recuperado de <http:// www.dominiopublico.gov.br/pesquisa/DetalheObraForm.do?select_action\&co obra $=1939>$.

Safatle, V. (2013). A moral psiquiátrica. Folha de S. Paulo, 01/10/2013. Recuperado de $<$ http://www1.folha.uol.com.br/colunas/vladimirsafatle/2013/10/1349847-a-moral -psiquiatrica.shtml>.

\section{Resumos}

(“Arrested for having dog arrested for not having dog!": Notes from The Alienist, by Machado de Assis)

The presentation and analysis of the famous novel "The Alienist" by the Brazilian writer Joaquim Maria Machado de Assis, published in 1882 in Papéis Avulsos, serves here as the basis for a brief discussion on the ideological and commercial aspects that orient current diagnostic and therapeutic procedures. These aspects, defined in psychiatric manuals, configure and establish a specific medical discourse and practice while, at the same time, produce both the drugs and the mental illness they supposedly combat.

Key words: Joaquim Maria Machado de Assis, literature, mental illness, ideology

("Arrêté pour avoir un chien, arrêté pour ne pas avoir de chien!": notes sur l'oeuvre $O$ alienista de Machado de Assis)

La présentation et l'analyse du célèbre conte "O alienista” de l'écrivain brésilien Joaquim Maria Machado de Assis, publié en 1882 dans Papéis avulsos, sert ici de support à une brève discussion sur les aspects idéologiques et de marché qui orientent les procédés de diagnostic et thérapeutiques actuels portant sur les psychopathologies. Ces aspects, incarnés dans les manuels psychiatriques, modèlent et établissent un 


\section{MOVIMENTOS LITERÁRIOS}

certain discours et une conduite médicale, mais produisent néanmoins aussi les drogues et les maladies mentales qu'ils prétendent combattre.

Mots clés: Joaquim Maria Machado de Assis, littérature, maladie mentale, idéologie

("Detenido por tener perro, arrestado por no tener perro!": Notas de $O$ alienista de Machado de Assis)

La presentación y análisis de la famosa novela "O alienista", del escritor brasileño Joaquim Maria Machado de Assis, publicadaen 1882 en Papéis avulsos, son usados como punto de partida de una breve discusión sobre los aspectos ideológicos $y$ de mercado que orientan los procedimientos diagnósticos y terapéuticos actuales de las psicopatologías. Dichos aspectos, presentados en los manuales psiquiátricos, conforman y establecen un determinado discurso y práctica médicos que construyen al mismo tiempo tanto las llamadas enfermedades mentales, como las drogas que supuestamente son capaces de eliminar.

Palabras claves: Joaquim Maria Machado de Assis, literatura, enfermedad mental, ideología

("Gefangen wegen Besitz eines Hundes, gefangen wegen nicht-Besitz eines Hundes!": Erläuterungen zum Werk $O$ alienista, vom brasilianischen Schriftsteller Machado de Assis)

Die Vorstellung und Untersuchung des bekannten Romans $\mathrm{O}$ alienista, des brasilianischen Schriftstellers Joaquim Maria Machado de Assis, 1882 veröffentlicht in der Sammlung Lose Blätter, wird hier als Grundlage für eine kurze Diskussion der ideologischen und marktwirtschaftlichen Aspekte genutzt, welche die aktuellen diagnostischen und therapeutischen Vorgehensweisen im Rahmen der Psychopathologien leiten. Diese Aspekte, in psychiatrischen Handbüchern festgehalten, bilden und formen eine ganz bestimmte Auffassung und ärztliche Handlungsweise. Gleichzeitig sind sie Grundlage zur Herstellung von Drogen und Schaffung geistiger Krankheiten, die sie angeblich bekämpfen.

Schlüsselwörter: Joaquim Maria Machado de Assis, Literatur, Geisteskrankheiten, Ideologie

Citação/Citation: Kon, N. M. (2014, março). "Preso por ter cão, preso por não ter cão!”: notas a partir de "O alienista", de Machado de Assis. Revista Latinoamericana de Psicopatologia Fundamental, 17(1), 132-142.

Editor do artigo/Editor: Ricardo Telles de Deus

Recebido/Received: 9.10.2013/ 10.9.2013 Aceito/Accepted: 18.12.2013/12.18.2013 
Copyright: (C) 2009 Associação Universitária de Pesquisa em Psicopatologia Fundamental/ University Association for Research in Fundamental Psychopathology. Este é um artigo de livre acesso, que permite uso irrestrito, distribuição e reprodução em qualquer meio, desde que o autor e a fonte sejam citados / This is an open-access article, which permits unrestricted use, distribution, and reproduction in any medium, provided the original author and source are credited.

Financiamento/Funding: A autora declara não ter sido financiada ou apoiada / The author has no support or funding to report.

Conflito de interesses/Conflict of interest: A autora declara que não há conflito de interesses / The author declares that has no conflict of interest.

\section{Noemi Moritz Kon}

Psicanalista; Membro do Departamento de Psicanálise do Instituto Sedes Sapientiae (São Paulo, SP, Br); Mestre e Doutora em Psicologia Social pelo Instituto de Psicologia da Universidade de São Paulo - USP (São Paulo, SP, Br); autora de Freud e seu duplo: reflexões entre psicanálise e arte (São Paulo: Edusp/Fapesp, 1996); A viagem: da literatura à psicanálise (São Paulo: Companhia das Letras, 2003) e organizadora de 125 contos de Guy de Maupassant (São Paulo: Companhia das Letras, 2009).

Rua Augusta, 2445, cj. 2

01413-100 São Paulo, SP

e-mail: noemi.m.kon@gmail.com 